

\title{
PAISAGEM CULTURAL DA IMIGRAÇÃO EM SANTA CATARINA
}

\author{
María Regina Weissheimer
}

Arquiteta e urbanista, superintendência do Iphan em Santa Catarina

\section{RESUMO}

A singularidade da paisagem cultural da imigração em Santa Catarina está grandemente alicerçada pela existência das pequenas propriedades rurais policulturas, de base familiar, que durante muito tempo obtiveram seu sustento através da venda de produtos tradicionais, feitos da matéria-prima produzida na propriedade e comercializado localmente. A partir da segunda metade do século $X X$, a crescente industrialização das regiões de imigração e a rápida transformação das cidades, cuja área urbana engole os antigos núcleos rurais, agravada pela imposição de regras sanitárias que restringem o produtor artesanal, passaram a criar sérios problemas à sobrevivência econômica da pequena propriedade rural. A preservação dos aspectos mais autênticos da paisagem cultural dessas regiões depende, atualmente, do desenvolvimento de alternativas econômicas para o sustento da pequena propriedade, incluindo a necessária criação de selos e certificações especiais aos produtos tradicionais.

Palavras chave: paisagem cultural, imigração, patrimônio cultural 


\section{RESUMEN}

La singularidad del paisaje cultural de la inmigración en Santa Catarina se sustenta en gran parte por la existencia de pequeñas propiedades rurales, basadas en la producción familiar, que han tenido durante mucho tiempo su sustento garantizado con la venta de productos tradicionales, elaborados a partir de materias primas producidas en la granja y comercializados localmente. A partir de la segunda mitad del siglo XX, la creciente industrialización de las regiones de inmigración y la rápida transformación de las ciudades, cuya área urbana se traga los antiguos centros rurales, agravada por la imposición de normas sanitarias que restringen el productor artesanal, han creado graves problemas para la supervivencia económica de las pequeñas propiedades. La preservación de los aspectos más auténticos del paisaje cultural en estas regiones depende actualmente el desarrollo de alternativas económicas para el apoyo de la pequeña propiedad, incluyendo la necesaria creación de sellos especiales y certificaciones a los productos tradicionales.

Palabras clave: paisaje cultural, inmigración, patrimonio cultural

\section{ABSTRACT}

The singularity of the immigration's cultural landscape in Santa Catarina is largely supported by the existence of small farms, mixed cropping and family-based, that for a long time had their livelihood by selling traditional products, made from raw materials produced on the farm and marketed locally. From the second half of the twentieth century, the growing industrialization and the rapid transformation of cities, whose urban area swallows the old rural centers, compounded by the imposition of sanitary rules restricting the artisan producer, have created serious problems for the economic survival of small farms. The preservation of the most authentic aspects of the cultural landscape in these regions depends, currently, on the development of economic alternatives for the small property support, including the necessary creation of special labels and certifications to traditional products.

Keywords: cultural landscape, immigration, cultural heritage 


\section{INTRODUÇÃO}

O Brasil é conhecido pela diversidade e riqueza das suas ocorrências naturais e das manifestações culturais que Ihe dão caráter singular no contexto mundial. Cada porção desse país de dimensões continentais é formada por uma miríade de expressões culturais de origens variadas -indígenas, africanos, europeus, asiáticos... Línguas, sotaques, culinária, arquitetura, celebrações, formas de cultivo, técnicas construtivas, tradição náutica, modos de vida... Influenciados pela tradição autóctone, condicionados pelos contextos naturais e geográficos, vinculados a questões políticas e econômicas, tradições culturais de todos os continentes encontraram em terras brasileiras um meio de se expressar e produzir especificidades locais que dão cores e vida a esta vasta porção de território que costumamos chamar de Brasil.

No sul do país, o processo de imigração de grupos europeus ocorrido entre meados do século XIX e meados do XX foi decisivo para formar um dos mais expressivos contextos culturais brasileiro. Com a vinda da Família Real e a Abertura dos Portos em 1808, a imigração de grupos estrangeiros passou a ser estimulada como política oficial de incremento à povoação, especialmente nas chamadas "terras devolutas", grandes porções de território ainda desprovidas de povoações oficiais - embora muitas vezes ocupadas por grupos indígenas -, localizadas em regiões interioranas, distantes do litoral já vastamente povoado e pontilhado de cidades.

A primeira colônia foi fundada oficialmente em 1818, no estado do Rio de Janeiro, denominada Nova Friburgo e constituída por uma maioria de imigrantes suíços. No entanto, foi na região sul, nos estados do Rio Grande do Sul, Paraná e Santa Catarina, que o projeto de colonização com imigrantes de origem europeia obteve maior êxito.

Na Europa dos séculos XVIII e XIX, estas transformações foram intensas e romperam relações seculares, provocando o crescimento desenfreado e a explosão demográfica das cidades e a paulatina diminuição populacional da área rural. Houve um quase colapso da agricultura e do artesanato. Milhões de pessoas viram-se subitamente desalojadas de seus lugares e de suas atividades tradicionais. A alternativa de engajamento na nova ordem era duríssima: trabalho bruto e sem garantias, em jornada de trabalho acima de 15 horas, vivendo sem qualquer garantia de trabalho, em condições mais do que precárias de higiene, saúde e moradia.

Neste contexto, a opção de milhões de pessoas foi emigrar. 
O Brasil foi um dos lugares escolhidos, e Santa Catarina um dos estados que mais se valeu das oportunidades surgidas para ampliar a ocupação do seu território e aumentar seu contingente habitacional. (VIEIRA FILHO, 2012)

Em 1824, foi fundada a colônia de São Leopoldo, no Rio Grande do Sul, de imigrantes alemães e, em 1828, a primeira colônia catarinense: São Pedro de Alcântara.

Contudo, foi a partir de 1850 que o projeto da imigração obteve maior impulso, em virtude da promulgação da chamada "Lei de Terras", que dava aos estrangeiros o direito de serem proprietários das terras que ocupassem - até aquele momento, havia uma espécie de concessão, com direito de uso, mas sem direito de propriedade. A partir de então, a criação de colônias - com todas as implicações dela derivadas, como a aquisição e demarcação de terras, a realização de campanhas publicitárias no exterior para incentivar a vinda de imigrantes ao Brasil, o transporte, o alojamento e a distribuição das terras para os recémchegados - passou a ser um negócio explorado por particulares.

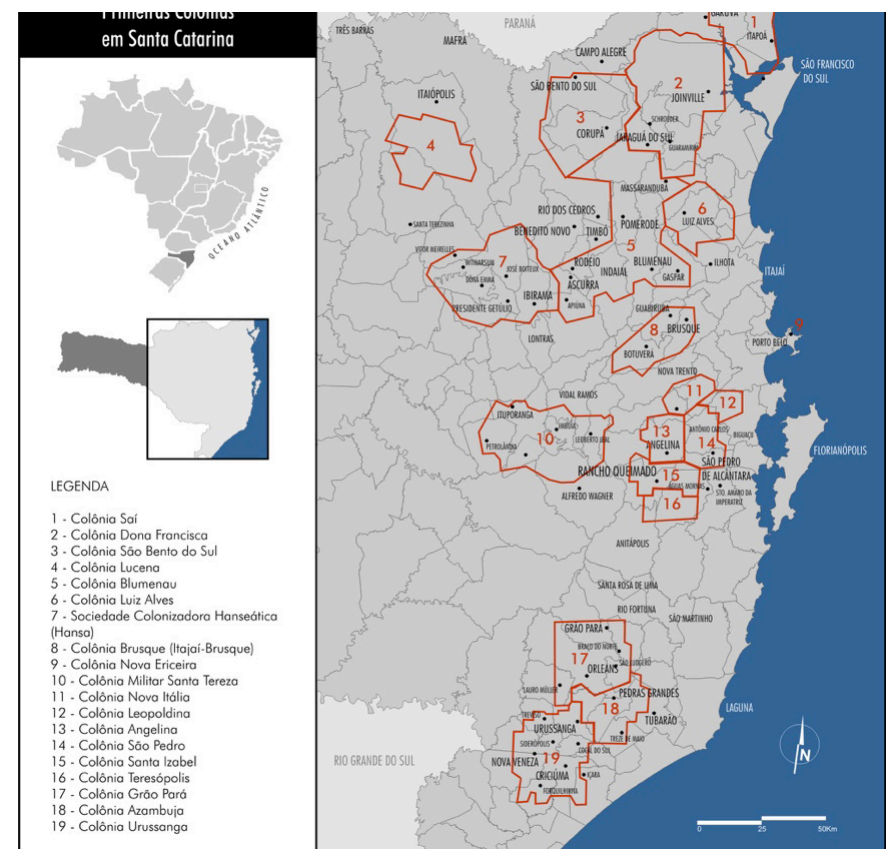

Mapa com as localização das principais colônias de imigrantes instaladas em Santa Catarina a partir de 1828. Fonte: VIEIRA FILHO, Dalmo; WEISSHEIMER, Maria Regina (org.). O patrimônio cultural da imigração em Santa Catarina. Brasília: IPHAN, 2012 
Em Santa Catarina, a Colônia Blumenau, implantada em 1850, foi a primeira de dezenas de colônias estabelecidas a partir da nova política de estímulo do governo brasileiro à imigração. Dentre os novos grupos que passaram a constituir o mosaico cultural brasileiro, no sul do Brasil destacaram-se os italianos, alemães e eslavos (poloneses e ucranianos).

Com a instalação das colônias de imigrantes, o painel cultural de Santa Catarina passou a ser distribuído mais ou menos da seguinte forma: no litoral, manteve-se a rede de cidades cuja população era predominantemente de origem portuguesa e africana (escravos), sendo que a população autóctone foi expulsa e praticamente extinta; próximo a Florianópolis, foram instaladas as colônias de São Pedro de Alcântara, Angelina e Santa Isabel, reunindo um grupo significativo de imigrantes alemães que passou a conviver com grupos locais já instalados ao longo da estrada que ligava a região do Caminho das Tropas, em Lages, com o litoral; o Vale do Itajaí, no interior do estado, constituiu-se de um número maior de imigrantes alemães, tendo como polo primordial a Colônia Blumenau, posteriormente incrementado pela Colônia Itajaí-Brusque (que deu origem à cidade de Brusque) e a Colônia Hansa (que originou a cidade de Jaraguá do Sul), para as quais foram, alguns anos mais tarde, levados grupos de italianos e poloneses, instalados sempre às bordas dos núcleos alemães; na região nordeste do estado, desenvolveuse a cidade de Joinville, originada da antiga colônia Dona Francisca, também constituída de maioria alemã; no planalto norte, destaca-se a extensão da Colônia Dona Francisca, que deu origem à cidade de São Bento do Sul, e na divisa com o Paraná localizaram-se os grupos de poloneses e ucranianos, centrados na colônia Lucena, atual município de Itaiópolis; por fim, a região sul catarinense passou a conviver com número expressivo de imigrantes italianos, que ocuparam as colônias de Urussanga, Azambuja e Grão-Pará.

\section{CARACTERIZAÇÃO DA PAISAGEM CULTURAL DA IMIGRAÇÃO}

Em cada um desses contextos regionais, a adaptação do imigrante às condições naturais, geográficas e econômicas da nova terra, aliada ao convívio com os demais grupos, resultou no desenvolvimento de soluções locais de ocupação do território, com características peculiares de instalação e desenvolvimento da pequena propriedade rural, da indústria familiar, da produção arquitetônica, de cultivo da terra e das mais variadas práticas culturais, passando pela culinária, pela adaptação da língua e preservação de dialetos. 


\section{O MODELO DE OCUPAÇÃO DO TERRITÓRIO}

Dentre as questões mais peculiares que singularizam a paisagem cultural da imigração no sul do Brasil está o modelo de ocupação territorial produzido a partir da instalação das colônias de imigrantes. Este modelo está baseado organização das colônias a partir de um núcleo central, geralmente um ponto de desembarque e recepção (como o antigo porto na cidade de Blumenau, às margens do Rio Itajaí-Açu, que ligava a colônia com o porto de Itajaí, por onde os imigrantes desembarcavam), de onde se originavam as estradas rurais que seguiam acompanhando cada uma das duas margens dos cursos d'água mais importantes, ao longo das quais estavam distribuídas os pequenos lotes de terra destinados aos imigrantes.

Cada núcleo de recepção consistia em um pequeno aglomerado urbano, que deu origem a dezenas de cidades de pequeno e médio porte que constituem ainda hoje a rede urbana que caracteriza as regiões de imigração (seja no Vale do Itajaí, em Santa Catarina, na Serra Gaúcha, no Rio Grande do Sul, ou em qualquer outro contexto da imigração, o mesmo modelo se repete).

Ao longo das estradas, margeando rios e cursos d'água, cortando os vales, se esparramavam as colônias rurais, formadas por uma sequencia de pequenos lotes de pouca testada e grande profundidade, onde eram instaladas as famílias de imigrantes. A testada dos lotes variava conforme o número de pessoas na família, mas todos, em geral, caracterizavamse por ser lotes estreitos e profundos, cuja testada fazia divisa com a estrada geral ou com o rio, caracterizada por terras planas cultivadas, onde eram instalados a casa principal e os ranchos de madeira que abrigavam os animais, serviam de depósito e onde eram guardadas as ferramentas de trabalho. Ainda na porção mais plana, desenvolviam-se as áreas de cultivo. As hortas, os jardins e os pequenos pomares dividem espaço entre si e localizam-se sempre nas proximidades da casa principal (à sua frente ou em suas laterais). Na subida dos morros, à medida que a topografia tornava-se acidentada, instalavam-se as áreas de pastagem, permanecendo a mata preservada nas partes altas e nas cumeadas, de onde se tirava de forma controlada a madeira para a construção de casas, ranchos e para a lenha necessária para a família. 


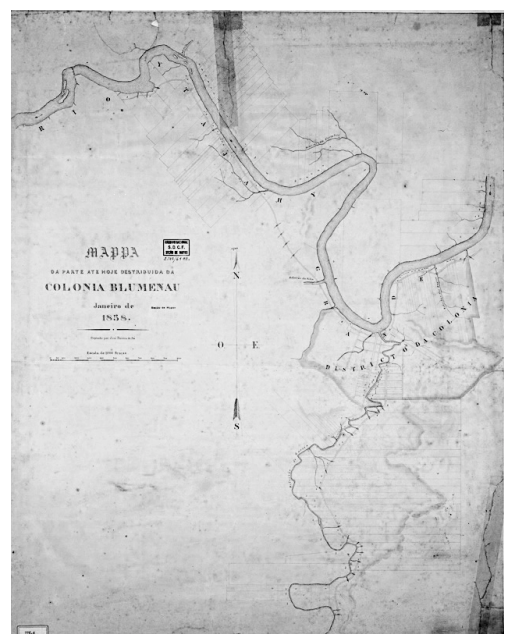

Mapa da Colônia Blumenau em 1858, com indicação da sede (distrito da colônia) e delimitação dos lotes ao longo do Rio Itajaí-Açu e do Ribeirão da Velha. Fonte: Arquivo Histórico Nacional
No entroncamento das estradas, estabeleciam-se as casas comerciais, pontos de referência não apenas para o comércio de mantimentos, mas para o recebimento de notícias, por meio de conversas, cartas e jornais, e para o encontro com vizinhos. Em certos casos, as casas comerciais contavam com serviços variados, como o oferecimento de empréstimos e favores financeiros, hospedagem e consultórios médicos.

Nas colônias alemãs, destacavam-se as sociedades recreativas, de música ou prática de esportes, sendo particularmente notáveis as Sociedades de Caça e Tiro (cuja tradição mantém-se viva na atualidade) e os salões de baile. A educação era um aspecto muito importante entre os alemães e, em virtude da inexistência de uma rede escolar consolidada entre os brasileiros, em todas as colônias alemãs foram construída escolas, ao lado das quais costumava-se a edificar também a casa do professor. Nas estradas rurais, nas proximidades das casas comerciais ou dos pequenos núcleos de referencia formados pelos salões, clubes e escolas, pontuavam-se também as igrejas, cuja tipologia de torre central, em alusão às igrejas góticas européias e pouco usual na tradição lusitana, passou a constituir-se como um marco referencial e simbólico da arquitetura religiosa, integrando posteriormente a paisagem de outros núcleos, não apenas de imigrantes.

O convívio social, que dentre os alemães tinha espaço nas casas comerciais, salões de baile e associações recreativas, entre os italianos e eslavos era preferencialmente vinculado à rotina religiosa. Nas colônias italianas, polonesas e ucranianas, a igreja ocupava espaço central na vida social, fator automaticamente transplantado para a organização urbana, centrada a partir da igreja.

A instalação das colônias produziu, assim, espaços urbanos e organização rural peculiares, distintas de todo o resto do território brasileiro. A grande rede de pequenas e médias cidades, situadas a poucos quilômetros umas das outras, é característica particular de todas as regiões de imigração. Mas as características mais notáveis da paisagem cultural da imigração encontram-se nas áreas rurais, constituídas pelas milhares de pequenas propriedades de base familiar, policultoras, espalhadas pelas centenas de estradas que serpenteiam os rios, cortando vales que, junto às áreas cultivadas, preservam paisagens exuberantes, de mata nativa e nascentes d'água que configuram recursos naturais ainda inigualáveis. 


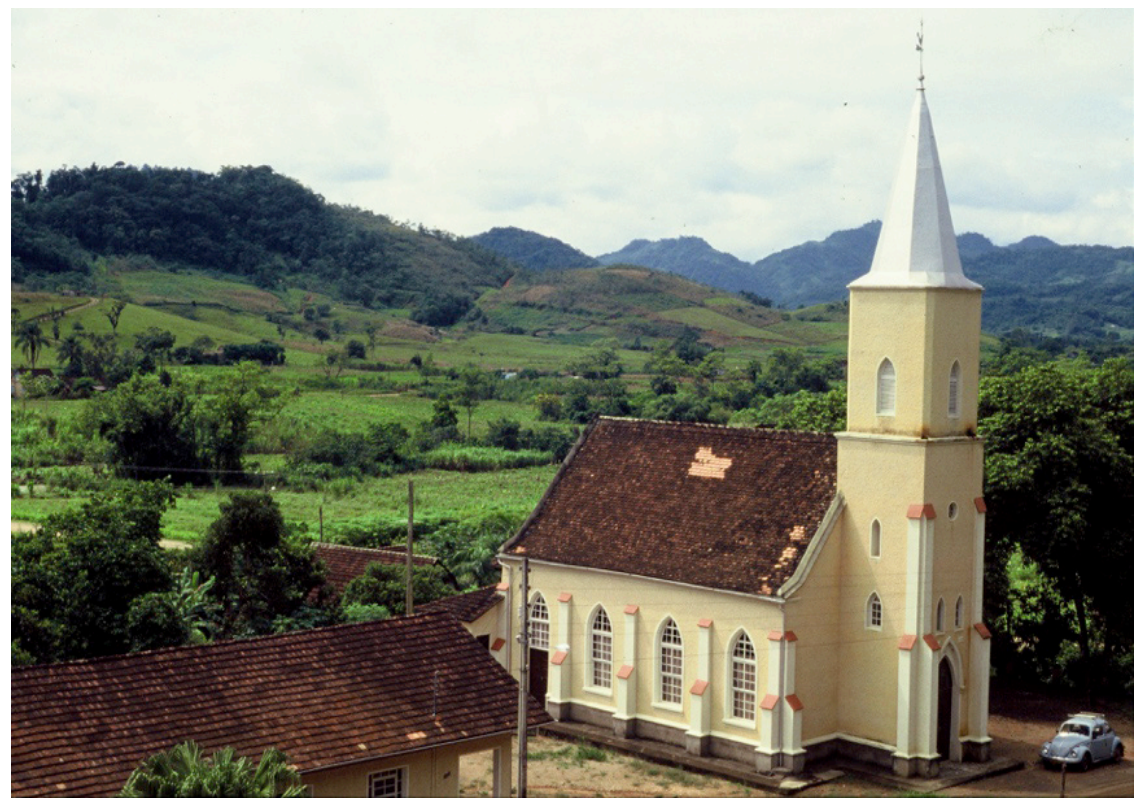

\section{ARQUITETURA}

A arquitetura é outro traço distintivo que singulariza a paisagem cultural da imigração no sul do Brasil. No novo continente foram reproduzidas as técnicas construtivas habituais dos países de origem dos imigrantes, adaptadas às condições naturais, climáticas e econômicas das novas terras. Em Santa Catarina, a arquitetura teuto-brasileira produzida nas colônias de imigrantes alemãs caracteriza-se pela predominância da técnica enxaimel, com fechamento em tijolos aparentes. Na região norte do estado, próxima às colônias polonesas, são expressivos os exemplares edificados em alvenaria autoportante de tijolos também aparentes, às vezes mesclados com o enxaimel ${ }^{1}$ e com abundante uso de madeira.

1 Enxaimel, ou Fachwerk, é uma técnica construtiva baseada em estrutura autônoma de madeira, feita com peças modulares pré-fabricadas, sequencialmente numeradas e montadas no local, cujos painéis de fechamento podem preenchidos por diversos tipos de material, sendo usual a taipa, o tijolo, a pedra ou a madeira. O Fachwerk possui origem muito remota e é encontrado em diversos países europeus, tendo muita expressividade em núcleos na Inglaterra, Alemanha, Polônia, Bélgica e norte da França, sendo transplantado pelos imigrantes para diversos países onde foram fundadas colônias. No Brasil, a técnica sofreu simplificações e adaptações que conferem características singulares à arquitetura local.
Igreja Luterana do núcleo rural de Testo Alto, em Pomerode. Fonte: Iphan/SC.
Mescla de tradições construtivas luso e teutobrasileiras na arquitetura residencial rural em São Bonifácio, na região da antiga Colônia São Pedro de Alcântara. Fonte: Iphan/SC

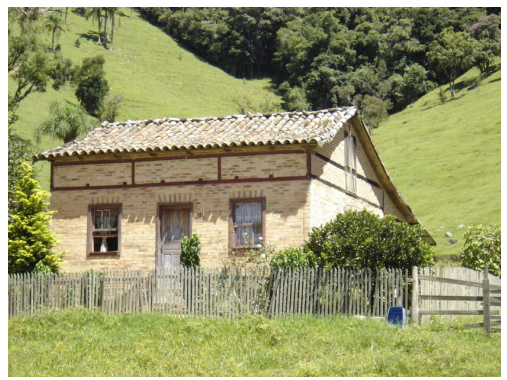


Vista panorâmica de Alto Paraguaçu, núcleo de imigração Polonesa no município de Itaiópolis, região norte de Santa Catarina. Foto: Maria Regina Weissheimer

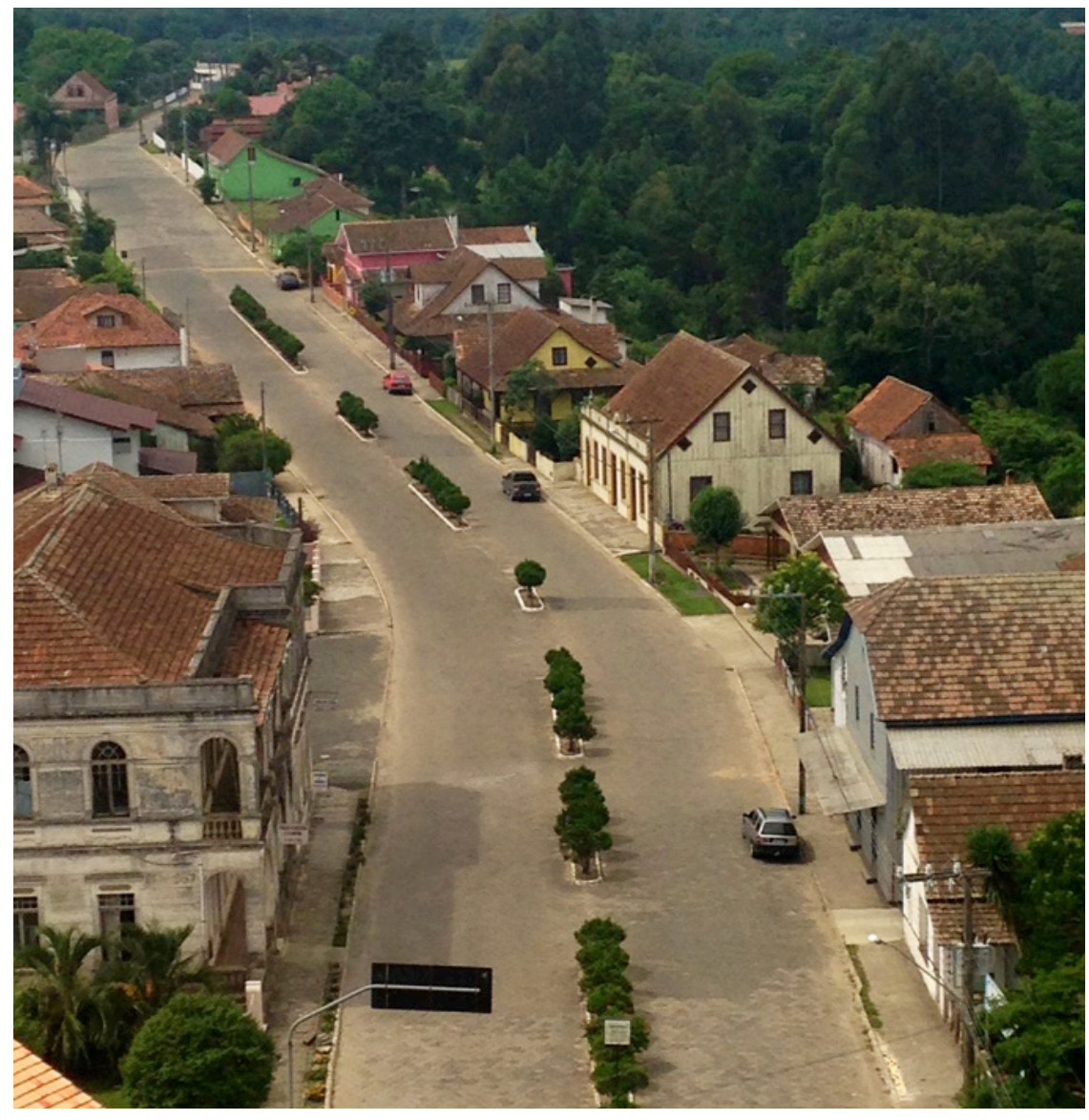

Na região sul, onde se concentraram as colônias italianas, passa a ser comum o emprego da alvenaria autoportante de pedra, aparente ou rebocada.

A taipa de mão também foi empregada na origem das colônias e, assim que foi possível o estabelecimento das olarias, logo substituída por tijolos. Nas colônias alemãs, destaca-se o emprego de telhas cerâmicas planas, usualmente chamadas de "rabo de castor", "telha germânica" ou simplesmente "telha chata". 

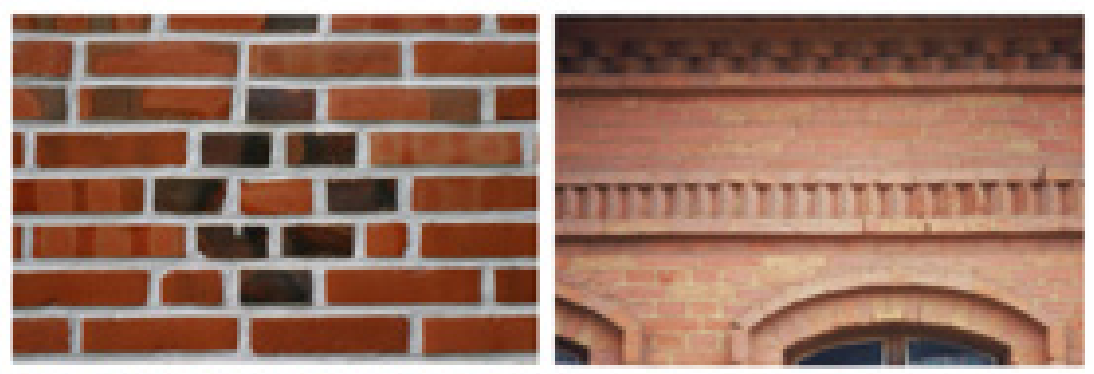

Detalhes construtivos: desenhos em paredes de alvenaria com tijolos aparentes e telha tipo "rabo de castor". Fonte: Iphan/SC
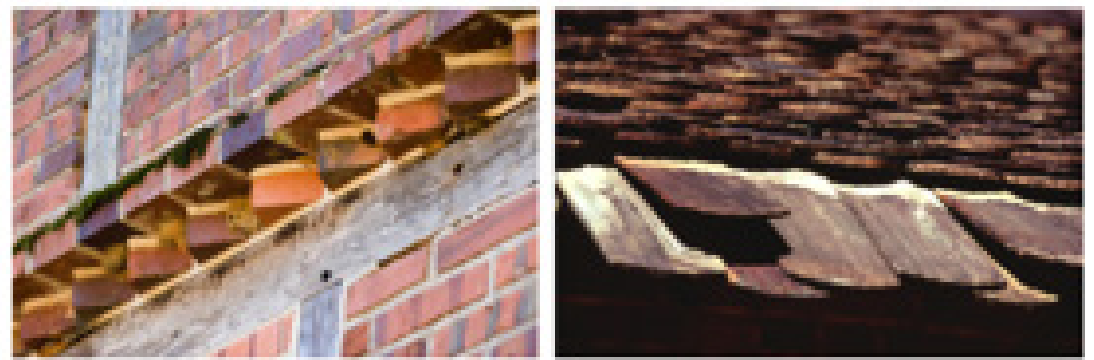

Cada uma das colônias, em cada região do estado, desenvolveu características arquitetônicas próprias, distintivas entre si, dependendo das regiões de origem dos imigrantes, do época da sua chegada, do convívio estabelecido com grupos já fixados anteriormente e das condições ambientais (geográficas, naturais, climáticas) locais.

Nas primeiras colônias, na região de São Pedro de Alcântara, próxima à capital Desterro (atual Florianópolis) foi comum a adaptação das técnicas construtivas ao emprego de materiais locais, especialmente no que se refere ao sistema construtivo, materiais e volumetria da cobertura. $\mathrm{Na}$ arquitetura teuto-brasileira, a cobertura é caracterizada por telhado de caibros armados, com inclinação de 45o, propícia ao emprego das telhas chatas, com aproveitamento do sótão para depósito ou uso como dormitório. Na região de São Pedro de Alcântara, a existência de materiais básicos, que já dispunham dos materiais básicos, tradicionalmente empregados na arquitetura luso-brasileira, a planta e a estrutura da casa alemã recebeu algumas adaptações, dentre as quais destaca-se a cobertura tipicamente brasileira, com inclinação menos acentuada, recoberta com telhas tipo capa e canal. 
Detalhes construtivos: uso da madeira nos detalhes de acabamentos. Fonte: Iphan/SC
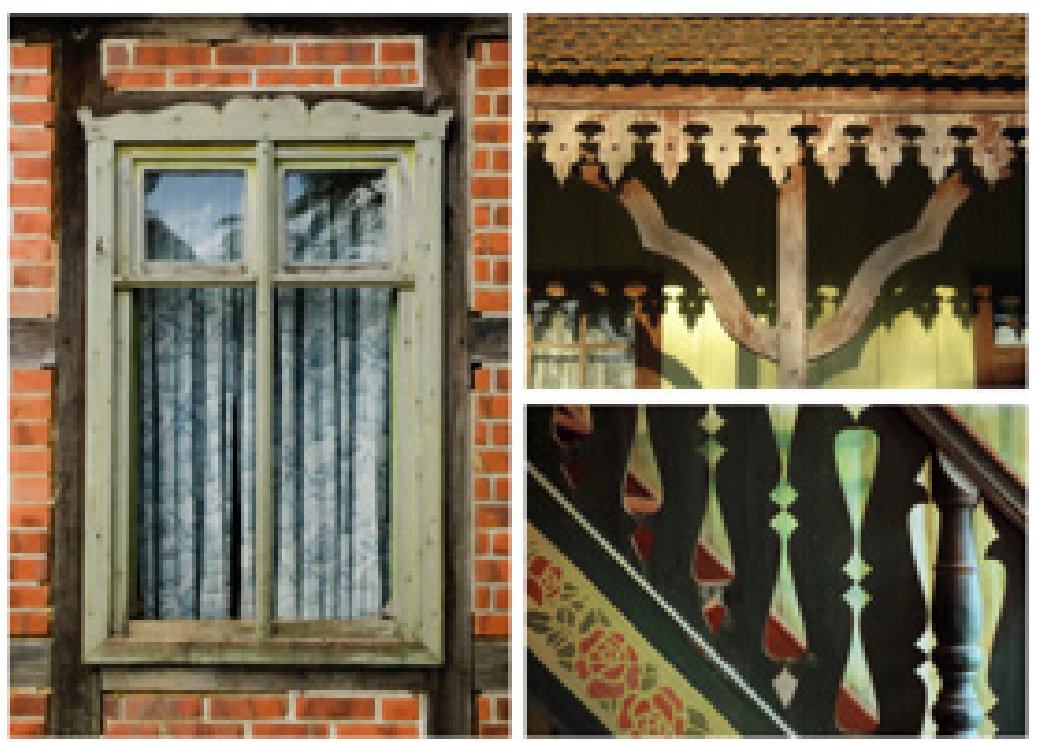

Já nas regiões onde as colônias foram praticamente os primeiros empreendimentos para a efetiva ocupação do território, distantes dos centros já consolidados, desenvolveu-se uma arquitetura mais parecida com aquela produzida nos países de origem, porém adaptadas aos contextos locais.

As variações decorrem da época em que foram edificadas, da origem dos construtores e do tipo de material disponível no local. A coloração dos tijolos, por exemplo, apresenta distinções e variações conforme o lugar de produção. No Vale do Itajaí, a terra avermelhada confere às edificações de tijolos aparentes uma tonalidade distinta daquela encontrada na região de Joinville, onde o solo é mais arenoso, resultando em tijolos de coloração mais pálida, com variações tonais produzidas a partir da diferença da queima.

Às características intrínsecas das técnicas e das adaptações locais, soma-se o esmero construtivo presente em todos os detalhes das edificações, da estrutura aos acabamentos. Em todas as regiões, são especiais os desenhos produzidos a partir da colocação diferenciada e da variação de tonalidades de tijolos. Lambrequins, mãos-francesas, encaixes, guarda- 
corpos, esquadrias... todos os elementos de madeira são cuidadosamente trabalhados e recebem atenção especial em todas as regiões de imigrantes, de todas as origens.

Do ponto de vista do uso, as construções podem ser classificadas em: arquitetura religiosa (igrejas e cemitérios), comercial (casas comerciais, aliadas ou não a hospedagem), recreativa (salões de baile e sociedades recreativas, no caso das colônias alemãs), escolar (especialmente os conjuntos de escola e casas do professor, também nas colônias de origem germânica) e residencial, neste caso havendo pequenas distinções entre o contexto urbano e o rural. Nas áreas rurais, a residência está sempre vinculada a um conjunto de ranchos de madeira que cumprem variadas funções, todas relacionadas com a produção da pequena propriedade.

\section{PEQUENA PRODUÇÃO RURAL, INDUSTRIALIZAÇÃO E URBANIZAÇÃO}

Dentre todos os aspectos, a persistência dos núcleos rurais é uma das características mais notáveis das regiões de imigração no sul do Brasil, baseados na existência das pequenas propriedades situadas ao longo das estradas que acompanham cursos d'água e serpenteiam os vales. A preservação da paisagem cultural da imigração, nos seus aspectos mais autênticos, depende da possibilidade de subsistência da pequena propriedade, com a manutenção do tipo de produção rural que lhe é característica.

Em geral, pode-se classificar o imigrante que chegava ao estado em dois tipos: o urbano e o rural. O primeiro já vivia em meio urbano em seu país de origem e desempenhava profissões variadas. Eram carpinteiros, alfaiates, açougueiros, funileiros, marceneiros, confeiteiros, chapeiros, torneiros, fundidores, músicos e tantos outros (Centenário de Blumenau, 1950), que transplantaram para o Brasil o conhecimento que possuíam dos ofícios. Este conhecimento resultou, em muitos casos, no desenvolvimento de pequenas indústrias locais, dando origem a polos industriais regionais que logo se tornaram referência no sul do Brasil. Em Santa Catarina, dezenas das indústrias - têxtil, moveleira, ceramista, metalúrgica - atualmente instaladas nas regiões de Blumenau, São Bento do Sul, Joinville e Jaraguá do Sul, por exemplo, se originaram da produção iniciada pelos imigrantes. 
O segundo tinha como principal ocupação, no seu país de origem, o cultivo da terra e a produção rural, passando a ser classificado na nova terra como lavrador. Chegado na colônia, estabeleceu-se nas áreas rurais, cultivando a terra e mantendo uma pequena criação de animais para produção das bases do sustento da família. Da pequena propriedade saía a produção de leite e alguns derivados (como os queijos e a coalhada), pães, bolos, biscoitos, doces, embutidos e defumados. Em alguns casos, instalavam-se pequenas indústrias rurais, baseadas na demanda e distribuição local.

Em todas as regiões de imigração, permanecem ainda vivas manifestações culturais de natureza imaterial trazidas pelos imigrantes, traduzidas no ainda frequente uso da língua ou de dialetos; no artesanato; na realização de festividades típicas, como as tradicionais Festas de Atiradores nas regiões de imigração alemã; e na imensa variedade de pratos e receitas que fazem parte do cotidiano alimentar.

Neste cenário, merecem especial atenção os produtos artesanais ou semi-industrializados como queijos, embutidos, doces, pães, biscoitos, geleias, defumados, conservas e bebidas fabricadas a partir da matéria prima produzida na pequena propriedade rural, que são base importante da economia familiar, atualmente colocada em xeque pela massificação e padronização da produção industrializada.

$\mathrm{Na}$ origem, a função urbana era complementada pela rural, e vice-versa. No entanto, à esteira do processo de desenvolvimento da indústria seguiu-se o acelerado crescimento urbano, que ao longo da segunda metade do século XX transformou radicalmente o cenário das cidades e também as paisagens rurais das regiões de imigração.

A crescente urbanização e expansão das zonas urbanas dos municípios provoca grande pressão nas áreas rurais que, na falta de medidas eficazes de controle e políticas públicas de valorização das pequenas propriedades, trará consequências irreversíveis nos próximos aos, implicando na completa descaracterização das paisagens rurais. Nos últimos vinte anos, todos os municípios do Vale do Itajaí, por exemplo, tiveram seu perímetro urbano estendido, incorporando antigos núcleos rurais que, de um dia para outro, passaram a ser tratados como zona urbana. Isso significa transformações imediatas no tipo de uso da terra, na cobrança de tributos municipais urbanos (como o IPTU), na pressão por parcelamento e instalação de infraestrutura urbana. 
Muitas áreas, ainda com feições e características rurais, sofrem com as pressões de um modelo de crescimento urbano baseado em uma noção desenvolvimentista nociva e que, em meio século, trouxe mais problemas do que benefícios a todas as regiões.

\section{OS ROTEIROS NACIONAIS DE IMIGRAÇÃO}

Diante da riqueza, diversidade e especificidades do patrimônio, material e imaterial, das colônias de imigrantes em Santa Catarina, o Instituto do Patrimônio Histórico e Artístico Nacional (Iphan) desenvolveu a partir de 1983 um amplo estudo, cujo objetivo era identificar o maior número possível de bens e buscar alternativas para a efetiva preservação deste conjunto imenso de bens e manifestações representativos do processo de imigração no sul do Brasil.

Deste trabalho resultou, em 2007, o dossiê que indicou para tombamento federal uma série de bens representativos das diversas expressões da arquitetura e da paisagem rural e urbana das regiões de imigração no estado catarinense, ao mesmo tempo que se solicitou o reconhecimento como paisagem cultural de dois pequenos núcleos rurais, que reuniam todos os elementos mais expressivos das manifestações materiais e imateriais que caracterizam as regiões de imigração.

Os núcleos rurais de Testo Alto, em Pomerode, e Rio da Luz, em Jaraguá do Sul, tiveram o tombamento proposto, conforme previsto pelo Decreto Lei no. 25/ 37 (unanimemente aprovado pelo Conselho Consultivo, juntamente com outros sessenta e um bens que integram o conjunto do patrimônio da imigração em Santa Catarina reconhecido como patrimônio nacional). No mesmo dossiê, foi indicado também o reconhecimento dos núcleos rurais como paisagem cultural. Tal proposta motivou a criação, no Iphan, de um grupo de trabalho encarregado de elaborar a minuta para a criação de instrumento voltado à preservação de paisagens culturais brasileiras, o que resultou no lançamento, em 2009, da Chancela da Paisagem Cultural Brasileira, regulamentada pela Portaria Iphan no. 127/09.

A proposta havia partido da constatação de que apenas o tombamento não era suficiente para garantir a preservação do patrimônio relacionado com a imigração, pois suas especificidades não repousam apenas nos aspectos materiais, mas em toda a dinâmica 
social, cultural e econômica que caracteriza a paisagem cultural dos núcleos rurais. Neste sentido, a sobrevivência da pequena propriedade ainda produtiva é fator primordial para permitir a permanência dos valores paisagísticos que distinguem e conferem autenticidade ao patrimônio da imigração.

Este tem sido, desde então, o principal desafio para a preservação das áreas onde estão situados os bens tombados. Em 2007, os objetivos elencados pelo projeto Roteiros Nacionais de Imigração representavam a base de um pacto de gestão compartilhada, do qual eram parceiros os principais agentes públicos envolvidos com a questão, nas três esferas governamentais: municipal, estadual e federal.

O Termo de Cooperação que instituiu formalmente os Roteiros Nacionais de Imigração foi assinado em âmbito federal pelos ministérios da Cultura, do Turismo e do Desenvolvimento Agrário, além do Iphan e do Serviço de Apoio às Micro e Pequenas Empresas (Sebrae); em âmbito estadual pelo próprio governador de Santa Catarina; e em âmbito municipal pelos prefeitos dos dezesseis municípios, de diversas regiões do Estado, onde o Iphan havia proposto o tombamento da série de bens. As ações previstas pelo acordo tinham como objetivo primordial a preservação e a valorização do patrimônio da imigração, visando:

- o reconhecimento do legado histórico dos imigrantes como integrante do patrimônio cultural do Brasil pelo Ministério da Cultura e pelo Instituto do Patrimônio Histórico e Artístico Nacional, e do patrimônio cultural do Estado de Santa Catarina pela Secretaria de Estado de Turismo, Cultura e Esporte, por meio da Fundação Catarinense de Cultura;

- a chancela de vários dos seus cenários urbanos e rurais como paisagens culturais brasileiras;

- o encaminhamento aos Conselhos Consultivos ou órgãos equivalentes do IPHAN, do Estado e dos Municípios envolvidos, do pedido de tombamento de uma série de bens representativos do processo de imigração em Santa Catarina, de acordo com os resultados obtidos em pesquisa realizada pelo IPHAN;

- o estabelecimento de legislações e medidas administrativas destinadas à preservação dos bens tombados, de suas áreas de entorno e da paisagem ambiental das regiões selecionadas; 
- a estruturação de caminhos rurais para o recebimento de fluxos turísticos compatíveis com suas possibilidades de absorção;

- o estabelecimento de pontos de recepção a visitantes e comercialização de produtos tradicionais;

- a criação de eco-museus, em conjunto com os municípios envolvidos e com o Estado de Santa Catarina;

- a qualificação dos museus e das bibliotecas municipais pelo MinC e pelo IPHAN e pela Secretaria de Estado de Turismo, Cultura e Esporte, por meio da Fundação Catarinense de Cultura, em conjunto com as prefeituras signatárias deste TERMO;

- a parceria entre órgãos federais, estaduais e municipais na implementação de políticas de preservação do patrimônio e de desenvolvimento econômico e social das regiões selecionadas;

- a divulgação do patrimônio integrante dos Roteiros Nacionais de Imigração, em âmbito internacional, nacional, regional e local;

- a valorização das pequenas propriedades, do arranjo produtivo local e, principalmente, da agricultura familiar.

\section{A IMPORTÂNCIA DA PEQUENA PROPRIEDADE PARA A PRESERVAÇÃO DA PAISAGEM CULTURAL DA IMIGRAÇÃO}

O projeto partiu do princípio de que a preservação do patrimônio cultural da imigração deve ter como base a manutenção da sua essência, não apenas da sua matéria. Para tanto, é preciso devolver à pequena propriedade alternativas de sustentabilidade econômica que Ihe foram retiradas nas últimas décadas, e oferecer ainda mais. Infelizmente, o projeto foi interrompido em virtude da descontinuidade que caracteriza a gestão pública no Brasil e da ainda inexistência de grupos ou associações civis que tomem para si a responsabilidade de buscar meios e alternativas para a implementação e continuidade das ações propostas.

Tanto os processos de urbanização, quanto a rápida e crescente industrialização da região, gerou imensas dificuldades à preservação das pequenas propriedades. Do ponto de vista produtivo, a legislação sanitária tem sido o maior empecilho à continuidade das pequenas 
produções artesanais ou semi-industriais. A legislação, criada com base na produção industrial em larga escala, com foco em grandes mercados e na exportação, ignora as especificidades dos pequenos produtores.

Em poucos anos, foram dizimadas as cervejarias artesanais originais que caracterizavam todos os núcleos de colonização alemã, por exemplo. A produção cervejeira, típica dessas regiões, agora vêm aos poucos encontrando uma nova possibilidade de existência, mas já não corresponde às mesmas pequenas cervejarias que desapareceram. Com base em uma legislação equivocada, voltada para a grande indústria e o consumo em massa, que nada tem a ver com as formas artesanais de produção, foram fechadas queijarias e pequenas empresas de embutidos, proibida a comercialização de doces e pães caseiros, colapsada a pequena propriedade rural.

Para poder continuar produzindo, o pequeno produtor foi forçado a promover adaptações gerais na sua propriedade, investindo recursos significativos na construção de unidades de produção azulejadas, com bancadas de alumínio, transformando radicalmente seu modo de produção, alterando as características finais do produto e onerando demasiadamente os custos da produção. Muitos desistiram.

Em 2010, visando complementar o trabalho iniciado com os inventários e o dossiê de tombamento, o Iphan desenvolveu pesquisa com enfoque nas cadeias produtivas de queijos, embutidos, pães, biscoitos e doces. O objetivo era a criação de certificação de qualidade, de origem ou de valor cultural que possibilitassem uma alternativa de geração de renda, por meio do reconhecimento do valor cultural associado às formas de produção e da íntima relação entre a pequena produção rural e a paisagem cultural das regiões de imigração.

A principal intenção foi identificar, através do estudo detalhado de toda a cadeia produtiva (desde a obtenção da matéria-prima até a comercialização para o consumidor final), quais eram os pontos frágeis e quais as características predominantes que conferem especificidade aos produtos artesanais ou semi-industrializados. Com base nos resultados e a partir de uma análise crítica da legislação corrente, pretendia-se a construção de formas alternativas de regulamentação, partindo do constatação de que a continuidade da pequena produção é fator primordial para a preservação da paisagem cultural da imigração no Sul do Brasil. 
Esse tipo de reconhecimento, que vem sendo amplamente utilizado no resto do mundo (como os diversos tipos de denominação de origem utilizadas na certificação de queijos, vinhos e embutidos de várias regiões da França, Itália, Suíça e Portugal, apenas para exemplificar), não tem sido devidamente explorado no Brasil.

Apenas recentemente o debate sobre a atualização da legislação, em favor da produção local e em pequena escala, tem ganhado espaço no cenário nacional. Diversos grupos e associações estudam formas de implantar no Brasil modelos de certificação de origem que possibilitem maior flexibilização nas regras impostas, permitindo a preservação de formas tradicionais de produção que vem se extinguindo. Um exemplo eloquente e que já obteve resultado concreto, foi a adaptação da legislação no Estado de Minas Gerais visando a certificação e comercialização do queijo da Serra da Canastra, produzido a partir do leite cru, não pasteurizado, cujo modo artesanal de produção foi reconhecido pelo Iphan como patrimônio cultural imaterial em 2008.

Em Santa Catarina, o kochkase - um tipo de queijo fundido produzido a partir do cozimento do leite cru, típico das regiões de imigração alemã - é um dos exemplos mais expressivos das dificuldades enfrentadas pelos pequenos produtores. A comercialização do kochkase foi proibida em todos os municípios em virtude da sua produção envolver a utilização do leite cru, não pasteurizado e, alegadamente, mais suscetível à existência de bactérias e elementos nocivos à saúde humana. O kochkase é, contudo, um dos produtos mais tradicionais das regiões de colonização germânica. Faz parte do cardápio cotidiano e sua presença é fundamental em todas as festividades. Aos poucos, criou-se um verdadeiro mercado clandestino do queijo, fato que atesta sua importância na cadeia alimentar e o alto grau de resistência dos seus consumidores habituais em substitui-lo ou modifica-lo.

Por isso, a partir de 2013 foi desenvolvido um projeto específico, em parceria com a Fundação Universidade de Blumenau (Furb), com o intuito de obter conhecimento aprofundado sobre o kochkase, suas formas tradicionais de produção e seu papel no mosaico cultural da imigração no Vale do Itajaí. A equipe multidisciplinar foi composta por profissionais da área de química, biologia, veterinária, nutrição, história e antropologia. A ideia foi desenvolver, tendo o kochkase como exemplo, um método de estudo da cadeia produtiva de um produto tradicional, que tem como base a produção familiar e em pequena escala, o que incluiu a realização de exames de laboratório e testes sensoriais, com a intenção de caracterizar 
todo o processo de produção e sanar possíveis problemas que pudessem colocar em risco a saúde dos consumidores. Ao final, seria possível a produção de um manual de boas práticas, permitindo, a partir disso, o desenvolvimento de uma certificação especial, voltada às especificidades do produto e de sua cadeia produtiva.

Um dos resultados mais importantes obtidos ao longo da pesquisa foi a comprovação de que as possíveis contaminações do queijo não são consequência da simples utilização do leite cru que, apesar de utilizado, passa por um processo de cozimento praticamente tão eficaz quanto a pasteurização, mas da existência de certas falhas no processo de obtenção do leite. Ao contrário das expectativas iniciais, a pesquisa demonstrou a existência de rebanhos não vacinados e em alguns casos, a falta de cuidados básicos de higiene na hora da ordenha, o que acaba precipitando todo o processo. Sanadas estas questões, é plenamente possível a continuidade da produção e da comercialização do queijo produzido com leite cru.

O exemplo do kochkase pode ser aplicado a todos os produtos tradicionais, cuja base produtiva é a pequena propriedade rural. Estes estudos e exemplos são a base para a construção de manuais de boas práticas e de uma legislação mais flexível, sensível às questões locais e aos aspectos culturais, sem a qual não será possível, a curto prazo, a efetiva preservação das paisagens culturais cuja singularidade esteja intimamente vinculada à pequena produção.

\section{CONSIDERAÇÕES FINAIS}

A experiência com o projeto Roteiros Nacionais de Imigração em Santa Catarina demonstra o grau de complexidade que caracteriza os processos de reconhecimento, proteção e gestão de paisagens culturais. Os mecanismos e atores envolvidos são absolutamente diversos e intimamente relacionados com a dinâmica e características próprias de cada paisagem cultural. Não há um modelo ou receita pré-definida capazes embasar a atuação de profissionais e órgãos governamentais na preservação das paisagens culturais. Mais que tudo, é preciso engajamento institucional, envolvimento com as comunidades e continuidade de ações. 


\section{ID_PESQUISAS}

O grau de complexidade das situações é, por outro lado, diretamente proporcional à quantidade de agentes a serem envolvidos para que seja possível delinear alternativas eficazes de preservação, o que torna todo o processo ainda mais moroso e angustiante, especialmente quando os já mencionados engajamento, envolvimento e continuidade encontram-se prejudicados.

O sinal positivo é de que, nos últimos anos, outros grupos vêm se somado às tentativas de construir alternativas econômicas à pequena propriedade e à regulamentação da produção artesanal na região. São exemplos positivos os trabalhos desenvolvidos pela Empresa de Pesquisa Agropecuária e Extensão Rural de Santa Catarina - Epagri e pelo grupo Rede Indicação Geográfica, que tem promovido eventos periódicos e buscando formas de construção de certificações de origem para os produtos rurais, aproveitando as recentes inovações da legislação brasileira e os trabalhos de indicação geográfica desenvolvidos pelo Instituto Nacional de Propriedade Intelectual. O Iphan tem buscado se aliar e contribuir com estes processos. 
ID_PESQUISAS

\section{REFERÊNCIAS BIBLIOGRÁFICAS}

BRASIL. Decreto Lei no. 25, de 30 de novembro de 1937. Disponível em http://www.planalto.gov.br/ ccivil_03/decreto-lei/del0025.htm

Centenário de Blumenau, 1850-1950. Blumenau: Edição da Comissão de Festejos, 1950.

IPHAN. Estudo sobre os produtos tradicionais da região de imigrantes em Santa Catarina. Florianópolis: IPHAN, 2010. [Documento interno, acesso restrito]

IPHAN. Portaria no. 127, de 30 de abril de 2009. Disponível em http://portal.iphan.gov.br/portal/ baixaFcdAnexo.do?id=1236

VIEIRA FILHO, D.; WEISSHEIMER, M. R. (org.). "O patrimônio cultural da imigração em Santa Catarina”. Brasília: IPHAN, 2012.

VIEIRA FILHO, D.; WEISSHEIMER, M. R. "Roteiros Nacionais de Imigração - Santa Catarina. Dossiê de Tombamento". Volumes 1 e 2. Florianópolis: IPHAN, 2007. Disponível em http://portal.iphan.gov.br/portal/ montarDetalheConteudo.do?id=17976\&sigla=Institucional\&retorno=detalhelnstitucional 